\title{
Traumatismes, douleurs, réhabilitation
}

\section{Jean Martin}

Dr méd., membre de la rédaction

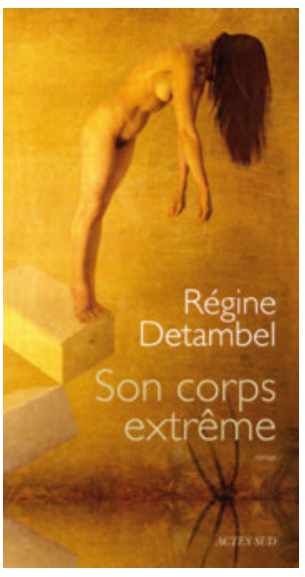

Régine Detambel

Son corps extrême

Paris: Actes Sud/Babel; 2011. 149 pages. 17.30 Euro.

ISBN 978-2-7427-9921-3

Physiothérapeute de formation, Régine Detambel (1963) se consacre aujourd'hui à l'écriture. ${ }^{1}$ Ce roman relate l'expérience d'une réappropriation de soi à travers son corps, suite à un traumatisme majeur (grave accident de voiture, peut-être un tentamen), chez une femme d'une cinquantaine d'années qui a vécu une enfance dénuée d'affection et une vie d'épouse et de mère qu'on peut dire ratée.

Histoire (longue, lente) de sa réémergence depuis le moment où elle se réveille très handicapée dans une unité de soins de polytraumatisés. C'est dans le rapport à ce corps en morceaux, à travers incapacités et douleurs, qu'elle reprend peu à peu la maîtrise de sa vie. Maîtrise du présent, grâce à l'amitié d'un collègue patient avec qui se forge une attirance sentimentale forte (un peu surprenant si on compare à tant de romances, cet ami rétabli repartira heureux vers femme et enfant - et l'héroïne maintiendra sa "renaissance»). Maîtrise aussi de moments de son passé dont elle revit les traumatismes. Dans les descriptions de handicaps à surmonter, Detambel tire profit de ses compétences professionnelles d'origine de physiothérapeute.

1 Dans un livre récent, elle développe la notion de bibliothérapie. Voir R. Detambel, Les livres prennent soin de nous Pour une bibliothérapie créative (Actes Sud, 2015). «Par le rythme et la musicalité de leurs phrases, le toucher sensuel de leur papier, les livres nous soignent et nous apaisent (...) Le livre permet d'élaborer ou de restaurer un espace à soi.»

jean.martin[at]saez.ch
Son maniement de la langue est remarquable. L'histoire débute avec une équipe de goudronnage travaillant de nuit, sous un ciel magnifiquement étoilé - là où a lieu l'accident. «La femme du chef d'équipe est aide soignante aux urgences, alors tout ça elle connaît bien, des hémorragies de ciel aux diarrhées d'étoiles en passant par les plaies ouvertes dans le magma stellaire (...) Sans compter les rêves des comateux. On lui en raconte de ces choses et elle écoute tandis qu'elle huile les coudes et les talons des agonisants. Penser à tout le savoir de sa femme réconcilie le chef d'équipe [qui tend à paniquer]. Sa femme lui parlerait comme aux malades des urgences, avec un pouvoir extraordinaire de vous calmer en égrenant les mots.»
«On ne s'éveille pas vierge d'un coma. Même si on a l'impression que tout est blanc, il y a eu les cauchemars. Les démons hantent le silence et s'en nourrissent (...) Elle somnole dans ce monde ouaté et glougloutant. Et le vide apparent dans son crâne tient à l'allongement inouï des temps de pose entre deux réflexions. Les heures se remplissent d'une sorte de matière sans valeur, de billes de polystyrène qui n'ont ni goût ni couleur. Alice jouit de n'avoir plus à décider du bien et du mal. Une merveilleuse dispense d'humanité.» A propos de son compagnon d'infortune: «Il n'est plus que son dos et une crampe dans les mâchoires, à force de serrer. Il est ses douleurs sourdes, pelotes sans origine, étrangères à toute orientation, plus vieilles que toute son expérience de la vie. Puis elles deviennent des rayons plus solaires, des douleurs-filles (...) A l'aube, la morphine de minuit n'agit plus et il serait incapable même de mimer la bonté, l'attention.» "Il confondait le sommeil de sa sieste et celui de la nuit, se réveillant égaré dans le temps, qui est pour un alité aussi dépourvu de repères que la haute mer.»

Quand des patients en réhabilitation ne progressent guère : «Ils picolent entre les crises. Les moines ne faisaient pas autrement. Ils se retiraient dans une cellule avec un matelas dur et un broc, et ils se repliaient sur eux-mêmes jusqu'au point précis où ils dépasseraient les tourments de l'humaine condition.» Quand, à force de soins, d'efforts et de temps, le mieux s'installe: «...fondent peu à peu les semelles de plomb. Pendant quelques mois, guérir est plus rapide que vieillir et même renverse la vapeur. Le regard aussi guérit, et le sourire.»

Sur les apports d'associations de patients: «A partir de là, tous les malades se réuniront dans la salle de rééducation. Cela leur fait l'effet de grandes vacances. S'y pressent des rhumatisants, des cancéreux, d'autres tombés eux aussi d'un toit, des migraineuses, des paraplégiques. Dans une bonne humeur spectaculaire, car il s'agit de parler de sa douleur; pas de celle ici et maintenant, mais bien de celle dont on s'est débarrassé. Avec pour devise: après la douleur, je sens venir le plaisir qui la suit.»

En conclusion, cette formule: "Que c'est bon quand quelqu'un vous écoute. Ne désespérez jamais de rien. Toute cendre est un pollen.» 